\title{
Long-term efficacy of intensive cycle ergometer exercise training program for advanced COPD patients
}

\section{Chaicharn Pothirat \\ Warawut Chaiwong \\ Nittaya Phetsuk \\ Chalerm Liwsrisakun \\ Chaiwat Bumroongkit}

Athavudh Deesomchok

Theerakorn Theerakittikul

Atikun Limsukon

Division of Pulmonary, Critical Care and Allergy, Department of Internal

Medicine, Faculty of Medicine, Chiang

Mai University, Chiang Mai, Thailand

Correspondence: Chaicharn Pothirat Division of Pulmonary, Critical Care and Allergy, Department of Internal Medicine, Faculty of Medicine, Chiang Mai University, Chiang Mai 50200, Thailand

Tel +66 53946228

Fax +66 $53895 \quad$ II

Email chaicharn.p@cmu.ac.th
This article was published in the following Dove Press journal:

International Journal of COPD

12 January 2015

Number of times this article has been viewed

Background: Exercise training has been incorporated into the international guidelines for the treatment of chronic obstructive pulmonary disease (COPD). However, the long-term efficacy of the training program for patients with advanced COPD has never been evaluated in Thailand.

Purpose: To determine the long-term efficacy of intensive cycle ergometer exercise program on various clinical parameters of patients with advanced COPD.

Materials and methods: The patients with advanced COPD were separated into two groups: the intensive ergometer exercise program group and the control group. The clinical parameters of all the patients were assessed at baseline, every month for the first 3 months, and then every 3 months until they had completed the 24-month follow-up. Mann-Whitney $U$ test was used to compare baseline mean differences between the groups. Repeated measure analysis was applied to determine the progress in all parameters during the entire follow-up period. Mean incase imputation method was applied to estimate the parameters of dropout cases.

Results: A total of 41 patients were enrolled: 27 in the intensive ergometer exercise program group and 14 in the control group. The intensive cycle ergometer exercise program group showed statistically significant improvements in muscle strength (from month 1 till the end of the study, month 24), endurance time (from month 1 till the end of measurement, month 12) and clinically significant improvements in 6-minute walk distance (from month 2 until month 9), dyspnea severity by transitional dyspnea index (from month 1 till the end of the study, month 24), and quality of life (from month 1 till the end of the study, month 24). There was no significant difference in survival rates between the groups.

Conclusion: The intensive ergometer exercise training program revealed meaningful long-term improvements in various clinical parameters for up to 2 years. These promising results should encourage health care professionals to promote exercise training for patients with advanced COPD who have limited daily activities despite optimal medication control.

Keywords: chronic obstructive pulmonary disease, pulmonary rehabilitation, ergometer training, physical endurance, strength training

\section{Introduction}

Exercise training program, an essential part of pulmonary rehabilitation, is now an integral part of the clinical management and health maintenance of patients with chronic obstructive pulmonary disease (COPD) who remain symptomatic or have continuous decline of pulmonary function despite standard medical management. The principal goals of exercise training are to reduce symptoms, decrease disability, and increase participation in physical and social activities, as well as improve quality of life (QoL) for individuals with chronic respiratory disease. ${ }^{1-4}$ In patients with advanced COPD, the beneficial effects of exercise training on exercise capacity, dyspnea, and QoL are 
well established..$^{5-7}$ American Thoracic Society (ATS) and European Respiratory Society (ERS) guidelines on diagnosis and management of COPD have emphasized the importance of exercise training for COPD patients with forced expiratory volume in the first second $\left(\mathrm{FEV}_{1}\right)$ below $80 \%$ of predicted value. ${ }^{8,9}$ Although pulmonary rehabilitation is widely practiced for patients with COPD in North America and parts of Europe, it is seldom applied in Thailand, ${ }^{10}$ and no exercise program has ever been evaluated for its long-term efficacy. We report for the first time the long-term efficacy of the exercise program for patients with advanced COPD in Thailand. Here, we describe the feasibility and benefits of the intensive ergometer training program called the Suandok Exercise Training (SET) program. The aim of the present study was to determine the long-term efficacy of the SET program on various clinical parameters (respiratory and peripheral muscle strength, exercise capacity, dyspnea severity, healthrelated QoL [HRQoL], and survival status) of patients with advanced COPD.

\section{Materials and methods Subjects}

Patients diagnosed with moderate, severe, or very severe COPD (GOLD stages II-IV) ${ }^{11}$ in a stable clinical condition (no exacerbation during the previous 6 weeks before being included in the study) and attending an outpatient chest clinic were enrolled. The inclusion criteria were patients aged over 40 years, ex-smokers with smoking history of $>10$ pack-years, history of exacerbation at least one time in the previous year, and willingness to follow the full course of exercise training program. Patients were excluded if they had long-term oxygen therapy, pneumonia during the previous 3 months, and cardiac disease or any other co-morbidities that limited exercise training. The study was approved by the Ethics Committees of the Faculty of Medicine, Chiang Mai University, and written informed consents were obtained from all the patients.

\section{Study design}

The patients were divided into SET or control group based on their preferences. All patients had been prescribed standard medical treatment for their COPD before and throughout the study period without any changes in the regular inhaled and/or oral bronchodilator and/or inhaled corticosteroid use. Patients underwent assessments at baseline, each month during the first 3 months, and then every 3 months till 24 months post intervention. Pulmonary function tests were determined by standard spirometer (Vmax series22,
Sensormedics) and reference values for a Knudson 1983. Spirometry parameters included forced vital capacity, $\mathrm{FEV}_{1}$, and the ratio of $\mathrm{FEV}_{1}$ to forced vital capacity. All tests were performed post bronchodilator according to ATS/ ERS guidelines. ${ }^{12}$ Exercise capacities were determined by the longest distance walk in 6 minutes (6-MWD) tested by a standard 6-minute walk test ${ }^{13}$ and endurance time measured by the longest duration self-paced walk on the treadmill. We measured patients' HRQoL using the St George's Respiratory Questionnaire (SGRQ) ${ }^{14}$ and dyspnea severity using both modified Medical Research Council (mMRC) ${ }^{15}$ and baseline/transition dyspnea index (BDI/TDI). ${ }^{16} \mathrm{We}$ measured patients' upper limb muscle strength using the stationary cycle ergometer (Monark, Rehab trainer $881 \mathrm{E}$, Varberg, Sweden) and lower limb muscle strength using the stationary bicycle (Monark, Ergomedic 828 E, Sweden). Maximal inspiratory pressure (MIP) as an indicator of inspiratory muscle strength ${ }^{17}$ was measured by Vmax series 22, Sensormedics. Patients completed pulmonary function tests, SGRQ, mMRC, BDI/TDI, upper limb and lower limb muscle strength, MIP, and 6-MWD at baseline and every month for the first 3 months, and then every 3 months until they completed the 24-month follow-up with the exception of the endurance time test, which was performed till the 12-month follow-up.

The SET program consisted of intensive and maintenance phases. The intensive phase was fully supervised by physiotherapists and nurses who conducted 16 sessions ( 2 sessions per week for 8 weeks). Each session included upper and lower limb cycle ergometer exercise training. Patients were trained on both stationary arm and leg ergometers. A brief warm up period of 10-15 minutes was performed before each training session. Instructions on correct stretching techniques and supervision of the patients throughout the entire training period were given. Exercise training during the first 2 weeks included arm and leg cycling trained for 30-40 minutes per session at mild intensity (30\%-35\% of heart rate reserve $[\mathrm{HRR}])^{18}$ and was evaluated weekly. Patients were instructed to pedal at a rate of 45-55 revolutions per minute and were encouraged to push themselves to the limits of their dyspnea, without exceeding a scale of 6 in the rating of perceived exertion (RPE) ${ }^{19}$ Exercise sessions were increased in duration and intensity by 5 minutes and $5 \%$ of HRR alternately every 2 weeks to reach a maximum of 50-60 minutes duration and $50 \%-55 \%$ of HRR during the last 2 weeks. Heart rate and finger pulse oxygen saturation $\left(\mathrm{SpO}_{2}\right)$ were monitored continuously throughout the training period and brief pause periods were determined according 
to the dyspnea level (RPE =6). Patients with de-saturation $\left(\mathrm{SpO}_{2}<90 \%\right)$ were trained using supplemental oxygen via a nasal cannula. A cool down period of 5-10 minutes was allowed after each training session. The maintenance phase lasted from months 3 to 24, and all patients in SET group were encouraged to continue doing their exercises at home without monitoring compliance. The control group was just encouraged to do self-exercise at home throughout the study.

\section{Outcome measures}

Study tests were performed by all patients at baseline and at month 1-3 and then every 3 months till they completed the 24-month follow-up except for the endurance test, which was performed until the 12-month follow-up.

Upper and lower limb muscle strengths were tested by progressive incremental tests performed on a station cycle ergometer. Each patient sat on the chair in front of the arm ergometer (Monark, Rehab trainer 881 E, Sweden) or on the bicycle (Monark, Ergomedic 828 E, Sweden). Work rate was then increased by 5 watts till the patient was unable to continue cycling by arms or legs. The heaviest load was recorded.

MIP was measured as an indicator of inspiratory muscle strength using techniques described by Black and Hyatt. ${ }^{17}$ MIP was defined as the largest negative (vacuum) sustained for 1 second against an occluded airway. Measurements were taken from residual volume. A minimum of ten maneuvers were performed for each measurement, with rest periods between maneuvers. All maneuvers were performed while sitting upright in a chair. The highest value was recorded.

The 6-minute walk test was performed in accordance with the instructions of the ATS, ${ }^{13}$ verbal encouragement was given and the distance was recorded. An increase of $54 \mathrm{~m}$ was considered a minimal clinically important difference (MCID). ${ }^{20}$

Endurance walk test was performed on a treadmill. Patients were instructed to walk for as long as they could at their selfpaced speed. The duration of walking in minutes was recorded. Exercise was terminated by the tester if the patient could walk no longer or reached the predicted maximum heart rate.

HRQoL was assessed by SGRQ. A change in a score of four points was defined as MCID change. ${ }^{21}$ Shortness of

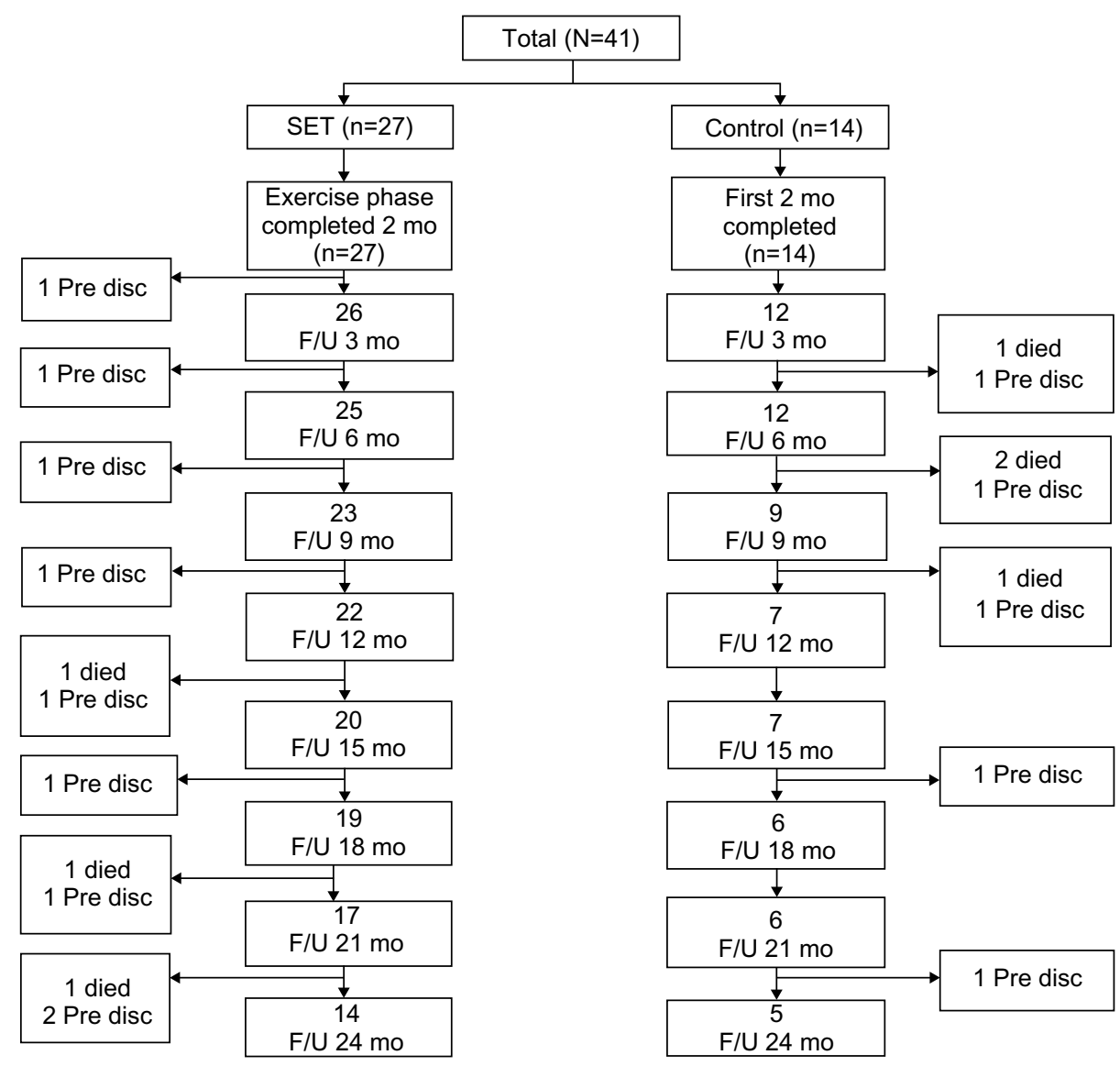

Figure I Flow-chart showing participation throughout the study.

Abbreviations: Pre disc, prediscontinuation; SET, Suandok exercise training; mo, months; F/U, follow-up. 
breath during activities of daily living was quantified by the mMRC and BDI/TDI scores; the MCID change of each score was defined as the score change of one point. ${ }^{22,23}$

\section{Sample size}

Sample size calculation was based on the difference in improvement in lower limb muscle strength (watt) between the experimental and the control group in our pilot study. In our pilot study, the response within each subject group was normally distributed with standard deviation 19 . The mean difference in the experimental and control groups was 22.6; we need to study 12 experimental and 12 control subjects to be able to reject the null hypothesis that the population means of the experimental and control groups are equal with probability (power) 0.8. The type I error probability associated with this null hypothesis is 0.05 , and anticipating a dropout rate of $20 \%$, we planned to randomly assign 14 per group.

\section{Statistical analysis}

We analyzed the results of the program in terms of changes in muscle strength, exercise capacity, degree of dyspnea, and QoL during and following the program. Results for numerical values were expressed as mean \pm standard deviation and those for categorical data were expressed as absolute frequencies and percentages. Mann-Whitney $U$ test was used to compare baseline mean differences between the groups. Repeated measure analysis was applied to determine the progress of all parameters during the entire follow-up period. Mean incase imputation method was applied to estimate the missing case parameters. MCIDs were set for 6-MWD, SGRQ score, mMRC, and BDI/TDI scores. Survival analyses were performed using the Kaplan-Meier product-limit method and comparison of the two groups with the log-rank test. Statistical significance was set at $P<0.05$. All analyses were carried out with the SPSS statistical package, version 16 for Windows.

\section{Results}

Forty-one patients meeting the inclusion criteria were enrolled (27 SET and 14 control). In the follow-up period, there were 13 and 9 dropouts in the SET and control groups, respectively. The reasons for the dropout cases were that seven patients died from acute exacerbation and 15 patients dropped out from lack of motivation on follow-up visits. In the SET group, there were three fatal cases (resulting from acute exacerbation with septic shock at 15 months, with respiratory failure at 21 and 24 months) and ten cases dropped out due to lack of motivation (each one at months $3,6,12,15,18$, and 21, and two cases at months 9 and 24). In the control group, there were four fatal cases (resulting from acute exacerbation with respiratory failure: two patients in month 2 and the other two patients at months 6 and 9) and five patients dropped out due to lack of motivation (each one at months 6, 9, 12, 18, and 24). The patients' disposition to dropout is shown in Figure 1. The baseline characteristics of the SET and control groups were comparable (Table 1). No significant changes in lung function and body mass index were observed throughout the follow-up period. The uses of inhaled medications were not different between the two groups.

Table I Baseline characteristics of subjects in the SET and the control group

\begin{tabular}{|c|c|c|c|}
\hline \multirow[t]{2}{*}{ Characteristics } & \multicolumn{2}{|c|}{ Total patients $(n=4 I)$} & \multirow[t]{2}{*}{$P$-value } \\
\hline & SET $(n=27)$ & Control $(n=14)$ & \\
\hline Sex M/F, n (\%) & $\begin{array}{l}12: 15 \\
(44.4: 55.6)\end{array}$ & $\begin{array}{l}7: 7 \\
(50.0: 55.0)\end{array}$ & 0.735 \\
\hline Age (years) & $71.9 \pm 6.4$ & $72.0 \pm 7.9$ & 0.858 \\
\hline Smoking (pack-years) & $36.5 \pm 23.4$ & $32.8 \pm 20.3$ & 0.923 \\
\hline BMI $\left(\mathrm{kg} / \mathrm{m}^{2}\right)$ & $19.3 \pm 4.3$ & $20.3 \pm 3.8$ & 0.316 \\
\hline $\begin{array}{l}\text { Exacerbations in } \\
12 \text { months before trial }(n)\end{array}$ & $2.1 \pm 1.7$ & $3.6 \pm 1.7$ & 0.649 \\
\hline $\begin{array}{l}\text { COPD admissions in } \\
12 \text { months before trial }(n)\end{array}$ & $1.9 \pm 1.1$ & $2.4 \pm I .1$ & 0.439 \\
\hline $\mathrm{FEV}_{1}$ (\% predicted) & $40.1 \pm 12.8$ & $44.2 \pm 16.7$ & 0.573 \\
\hline $\mathrm{FEV}_{\mathrm{I}} / \mathrm{FVC}(\%)$ & $55.2 \pm 14.3$ & $54.2 \pm 10.8$ & 0.869 \\
\hline COPD GOLD Stage III-IV & $18(66.7)$ & $8(57.1)$ & 0.511 \\
\hline $\mathrm{SaO}_{2}(\%)$ & $92.7 \pm 4.9$ & $91.7 \pm 5.6$ & 0.330 \\
\hline $\mathrm{PaO}_{2}(\mathrm{mmHg})$ & $71.4 \pm 14.4$ & $67.2 \pm 10.8$ & 0.328 \\
\hline Hct $(\%)$ & $46.2 \pm 6.4$ & $44.3 \pm 9.0$ & 0.606 \\
\hline 6-MWD (m) & $227.1 \pm 86.4$ & $23 I . I \pm I I 4.8$ & 0.880 \\
\hline SGRQ score & $55.5 \pm 21.0$ & $61.4 \pm 10.8$ & 0.752 \\
\hline $\mathrm{mMRC}$ score & $2.4 \pm 1.2$ & $2.2 \pm 0.8$ & 0.518 \\
\hline BDI score & $5.1 \pm 2.8$ & $4.5 \pm 2.2$ & 0.739 \\
\hline $\operatorname{MIP}\left(\mathrm{cmH}_{2} \mathrm{O}\right)$ & $47.8 \pm 24.6$ & $49.9 \pm 23.8$ & 0.967 \\
\hline $\begin{array}{l}\text { Upper limb strength } \\
\text { (Watt) }\end{array}$ & $49.3 \pm 23.6$ & $53.2 \pm 24.8$ & 0.489 \\
\hline $\begin{array}{l}\text { Lower limb strength } \\
\text { (Watt) }\end{array}$ & $55.3 \pm 27.0$ & $58.8 \pm 19.0$ & 0.619 \\
\hline Inhaled medications $\mathrm{n}(\%)$ & & & \\
\hline LAAC & $8(29.6)$ & $4(28.6)$ & 0.864 \\
\hline ICS + LABA & $4(14.8)$ & $3(2 \mid .4)$ & \\
\hline$I C S+L A B A+L A A C$ & $15(55.6)$ & $7(50.0)$ & \\
\hline
\end{tabular}

Note: Data are $\mathrm{n}(\%)$ or mean \pm standard deviation.

Abbreviations: SET, Suandok exercise training; M, male; F, female; BMI, body mass index; COPD, chronic obstructive pulmonary disease; FEV $(\%$ predicted), percentage predicted of forced expiratory volume in first second; $F E V_{1} / F V C$, ratio of FEV, to FVC; FVC, forced vital capacity; GOLD, Global initiative for chronic Obstructive Lung Disease; $\mathrm{SaO}_{2}$, oxygen saturation; $\mathrm{PaO}_{2}$, partial pressure of oxygen in arterial blood; Hct, hematocrits; 6-MWD, 6-minute walk distance; SGRQ, St George's Respiratory Questionnaire; mMRC, modified Medical Research Council; $\mathrm{BDI}$, baseline dyspnea index; MIP, maximal inspiratory pressure; LAAC, long-acting anticholinergics; ICS, inhaled corticosteroids; LABA, long-acting beta2-agonists. 


\section{Effect on muscle strengths}

Upper and lower limbs muscle strength

After 4 weeks of training, only patients in SET group had statistically significant improvements in upper and lower limb muscle strengths ( $P=0.017$ and 0.003 , respectively). The improvement was maintained till the end of the follow-up period (Figure 2A and B). Significant differences between the groups were detected at months 3, 6, 9, and 24 in upper limb muscle strength, and in all of the follow-up visits in lower limb muscle strength $(P<0.05)$.

\section{Respiratory muscle strength}

After 4 weeks of training, only patients in the SET group had statistically significant improvements in MIP
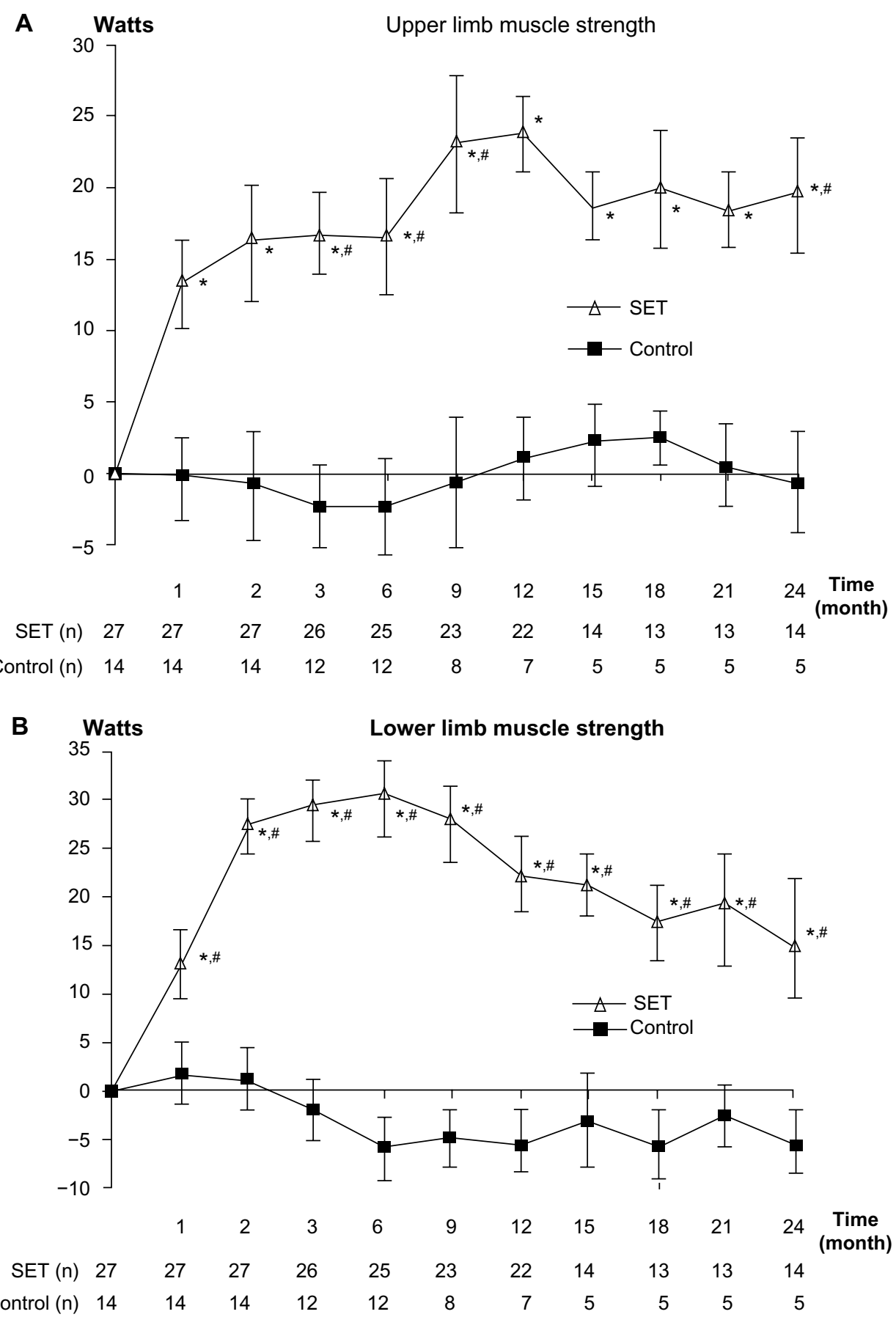

Figure 2 (Continued) 


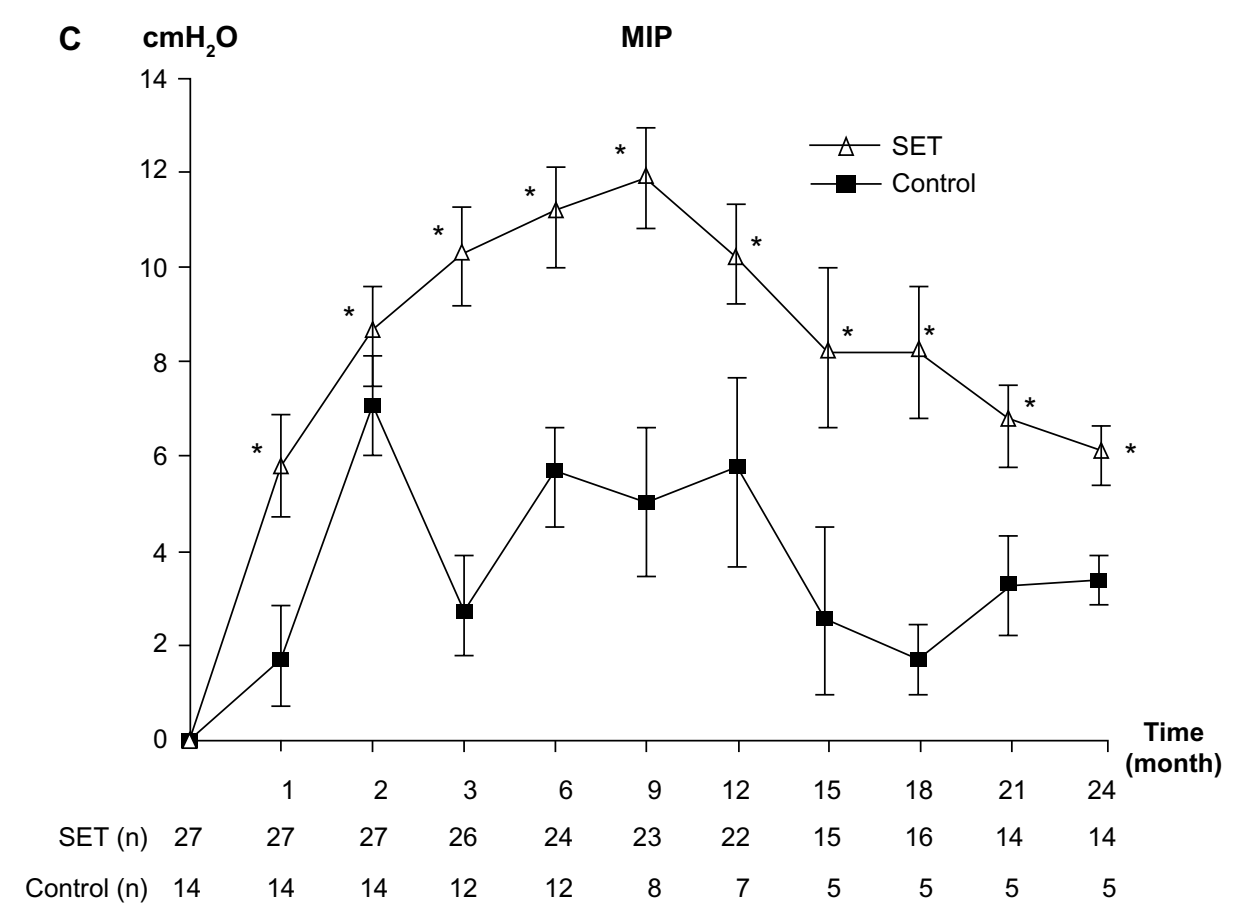

Figure 2 Change from baseline over 24 months in muscle strength.

Notes: (A) Change from baseline over 24 months in upper limb muscle strength. (B) Change from baseline over 24 months in lower limb muscle strength. (C) Change from baseline over 24 months in respiratory muscle strength. Values and error bars represent the mean \pm standard error. Within-group change from baseline; $* P<0.05$. Comparison between patients with SET and control groups; ${ }^{*} P<0.05$.

Abbreviations: MIP, maximum inspiratory pressure; SET, Suandok exercise training.

and the gains were maintained throughout month 24 (Figure 2C). There were no significant differences between the groups $(P=0.69)$.

\section{Effect on exercise capacity}

After 8 weeks of training, only patients in the SET group had clinically significant improvement in 6-MWD. The improvement was maintained until month 9 (Figure 3A). No statistically significant differences between the groups were detected throughout the follow-up period ( $P=0.065)$.

After 4 weeks of training, only patients in the SET group had statistically significant improvement in endurance time $(P<0.01)$. The improvement was maintained throughout the testing period (month 12; Figure 3B). Significant differences between groups were also detected at all follow-up visits $(P<0.01)$.

\section{Effect on breathlessness}

The dyspnea score by mMRC did not show clinically significant differences in both groups and the statistical significant differences between groups were only detected at months 3, 6, and $9(P<0.05$; Figure 4A). However, the dyspnea score showed clinically significant changes by TDI only in the SET group at all follow-up visits and so did the statistical significant differences between the groups $(P<0.01$; Figure 4B).

\section{Effect on HRQoL}

After 4 weeks of training, only patients in the SET group had clinically significant improvements in SGRQ score. The improvement was maintained till the end of follow-up period (Figure 5). The patients in the control group had clinically significant improvements in SGRQ score only in months 3 and 21. The statistically significant differences in SGRQ score between the groups were detected at all follow-up visits $(P=0.004)$.

\section{Effects on survival}

The overall survival curves for both groups are shown in Figure 6. After 2 years of follow-up, 34 of the original 41 patients were alive (survival rate, $82.9 \%$ ), 24 of the 27 patients in the SET group (88.9\%) and 10 of the 14 patients in the control group (71.4\%). The difference in survival rate of the patients between the groups was not statistically significant $(P=0.092)$.

\section{Discussion}

Exercise training, a multidisciplinary and structured intervention for patients with chronic pulmonary diseases has 


\section{A 6-MWD}

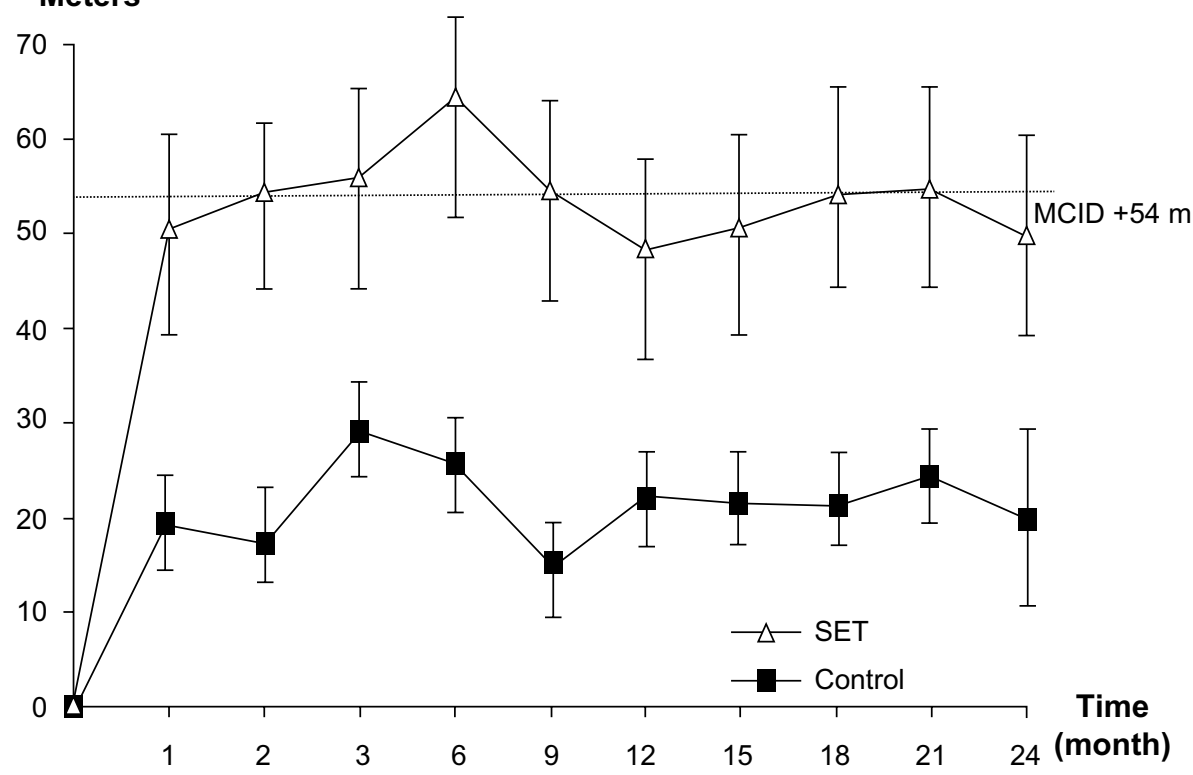

$\begin{array}{rrrrrrrrrrr}\text { SET (n) } 27 & 27 & 27 & 26 & 25 & 23 & 22 & 14 & 13 & 13 & 14 \\ \text { Control (n) } 14 & 14 & 14 & 12 & 12 & 8 & 7 & 5 & 5 & 5 & 5\end{array}$

\section{B Minutes Endurance time}

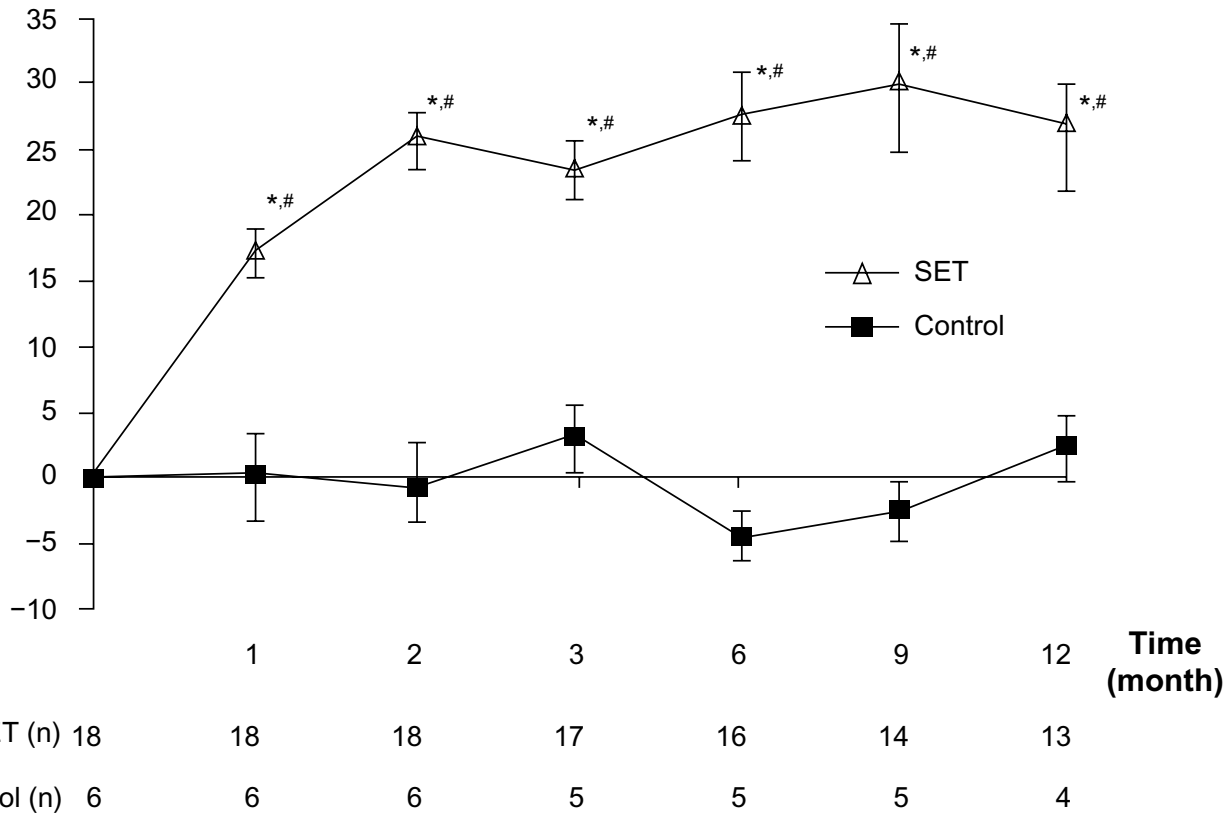

Figure 3 Change from baseline over 24 months in exercise capacities.

Notes: (A) Change from baseline over 24 months in 6-MWD. (B) Change from baseline over 12 months in endurance time. Values and error bars represent the mean \pm standard error. Within-group change from baseline in 6-MWD. Within-group change from baseline in endurance time; $* P<0.05$. Comparison between patients with SET and control groups; ${ }^{*} P<0.05$.

Abbreviations: 6-MWD, 6-minute walk distance; SET, Suandok exercise training; MCID, minimal clinically important difference.

been shown to improve exercise tolerance, reduce dyspnea, and improve HRQoL. Exercise training represents the cornerstone of every pulmonary rehabilitation program. ${ }^{24}$ This study indicates definite benefits of intensive ergometer exercise training for patients with advanced COPD as compared to the patients who participated in the control group. Our study reveals that ergometer exercise training produced both clinically meaningful and statistically significant improvements in respiratory and peripheral muscle strength, exercise capacity, degree of dyspnea (by BDI/TDI), and 


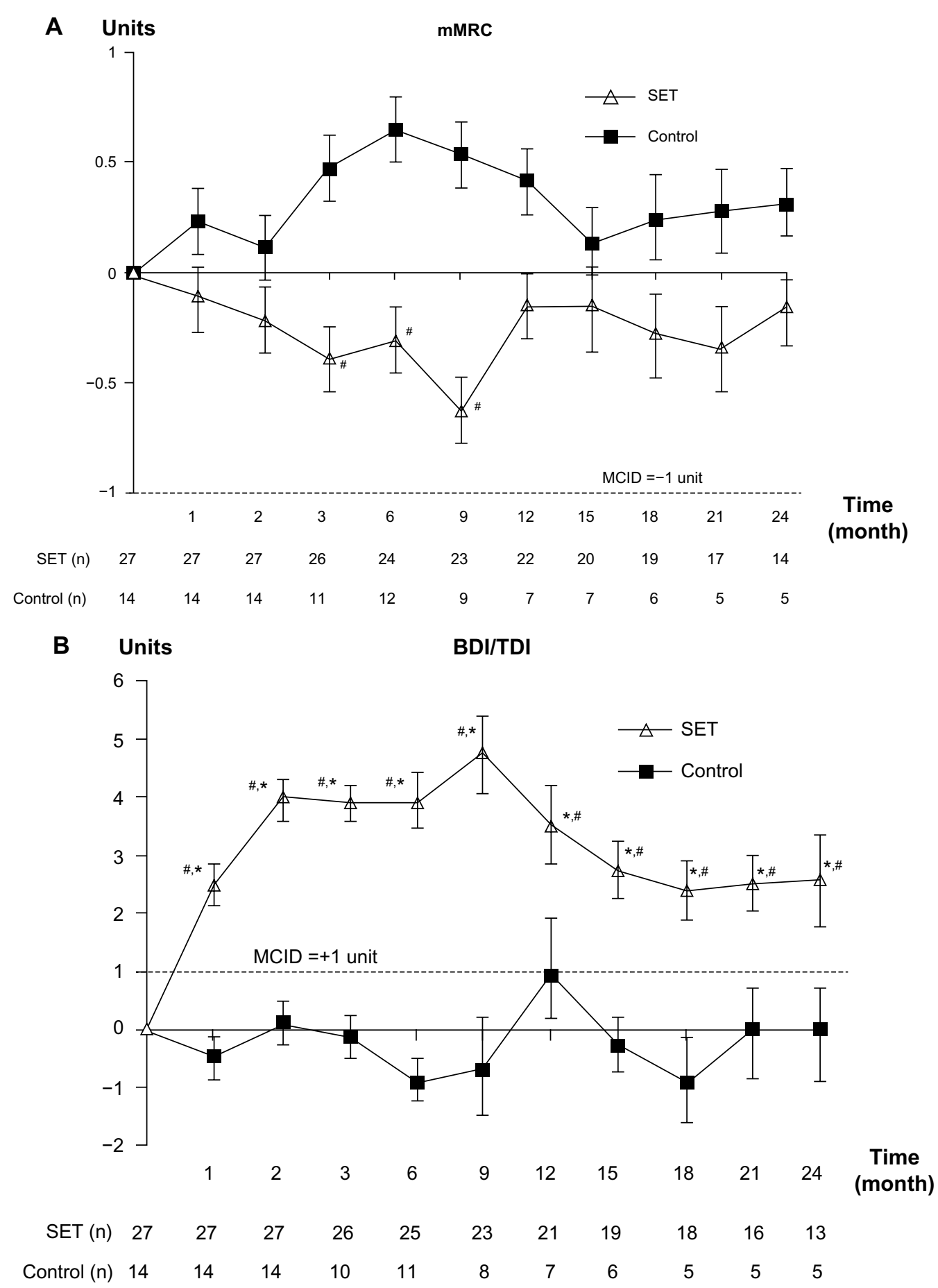

Figure 4 Effect on breathlessness.

Notes: (A) Change from baseline over 24 months in mMRC score. (B) Change from baseline over 24 months in TDI score. Values and error bars represent the mean \pm standard error. Within-group change from baseline in TDI; *MCID + I unit. Comparison between patients with SET and control groups; ${ }^{*}><0.05$.

Abbreviations: mMRC, modified Medical Research Council; TDI, transitional dyspnea index; SET, Suandok exercise training; MCID, minimal clinically important difference; $\mathrm{BDI}$, baseline dyspnea index.

HRQoL, even though no significant effect was observed on survival outcome. Exercise intensities were started from mild-to-moderate ( $30 \%-35 \%$ to $50 \%-55 \%$ of HRR) and duration of exercise was increased from $30-40$ minutes to 50-60 minutes per session. The guidelines of American College of Sports Medicine (ACSM) recommended that the training intensity should be targeted at $50 \%-80 \%$ of the maximal oxygen uptake or HRR for endurance exercise. ${ }^{25}$ The ACSM also advised to sustain intensity for 20-45 minutes and to stop cycling for 2-3 minutes during cycle ergometry when the breathlessness reaches 5-6 RPE because interval training is well accepted and shows similar 


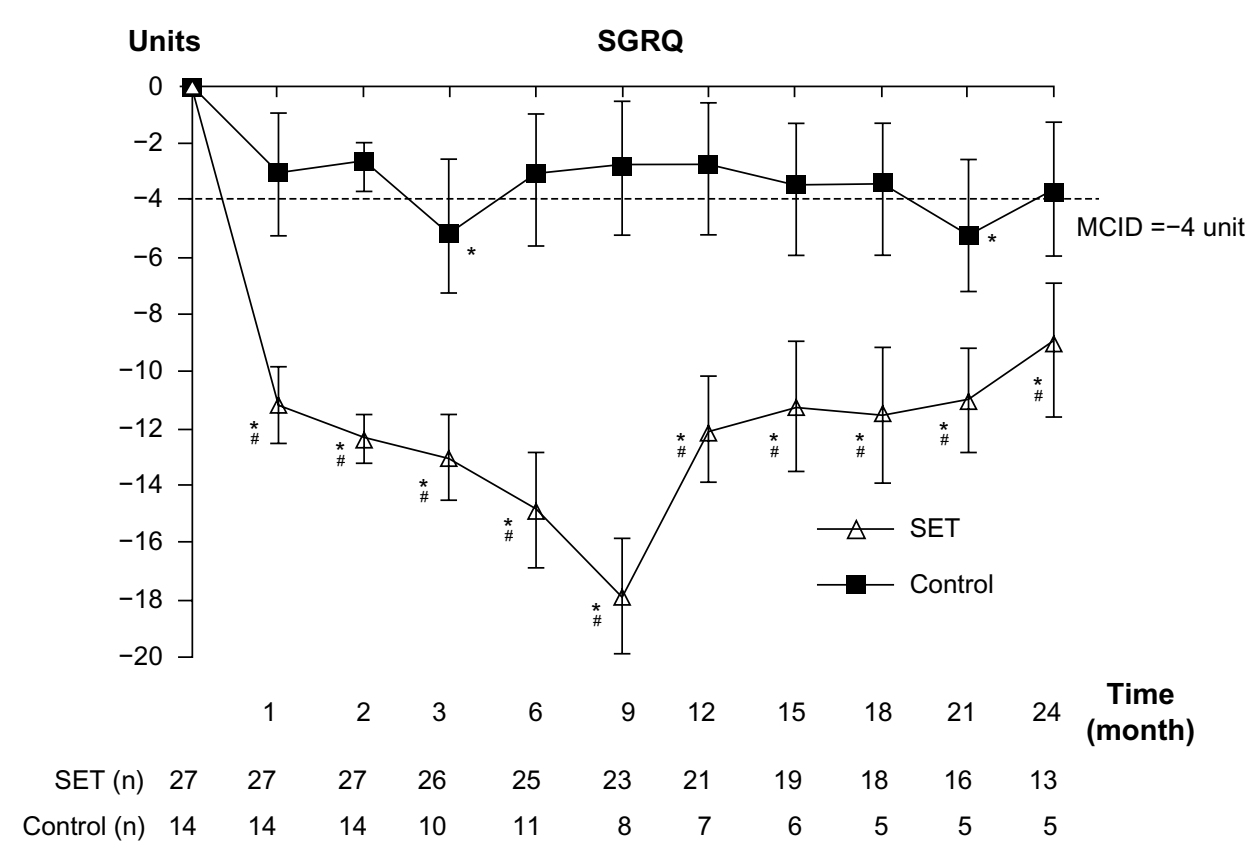

Figure 5 Effect on HRQoL.

Notes: Change from baseline over 24 months in SGRQ score. Values and error bars represent the mean \pm standard error. Within-group change from baseline; *MCID -4 unit. Comparison between patients with SET and control groups; ${ }^{*}<<0.05$.

Abbreviations: HRQoL, health-related quality of life; SGRQ, St George's Respiratory Questionnaire; SET, Suandok exercise training; MCID, minimal clinically important difference.

improvements in patients with severe COPD. ${ }^{26}$ Few studies have been able to demonstrate the long-term maintenance of benefits beyond 2 years ${ }^{5,6,27-30}$ but our study has confirmed that most of the benefits of the SET program were well maintained throughout the 24-month follow-up.
In our study, there were statistically significant improvements in respiratory muscle, upper and lower limb muscle strengths, endurance time, and clinically and statistically significant improvements in BDI/TDI, and QoL since the first month after SET was started, except the 6-MWD, which

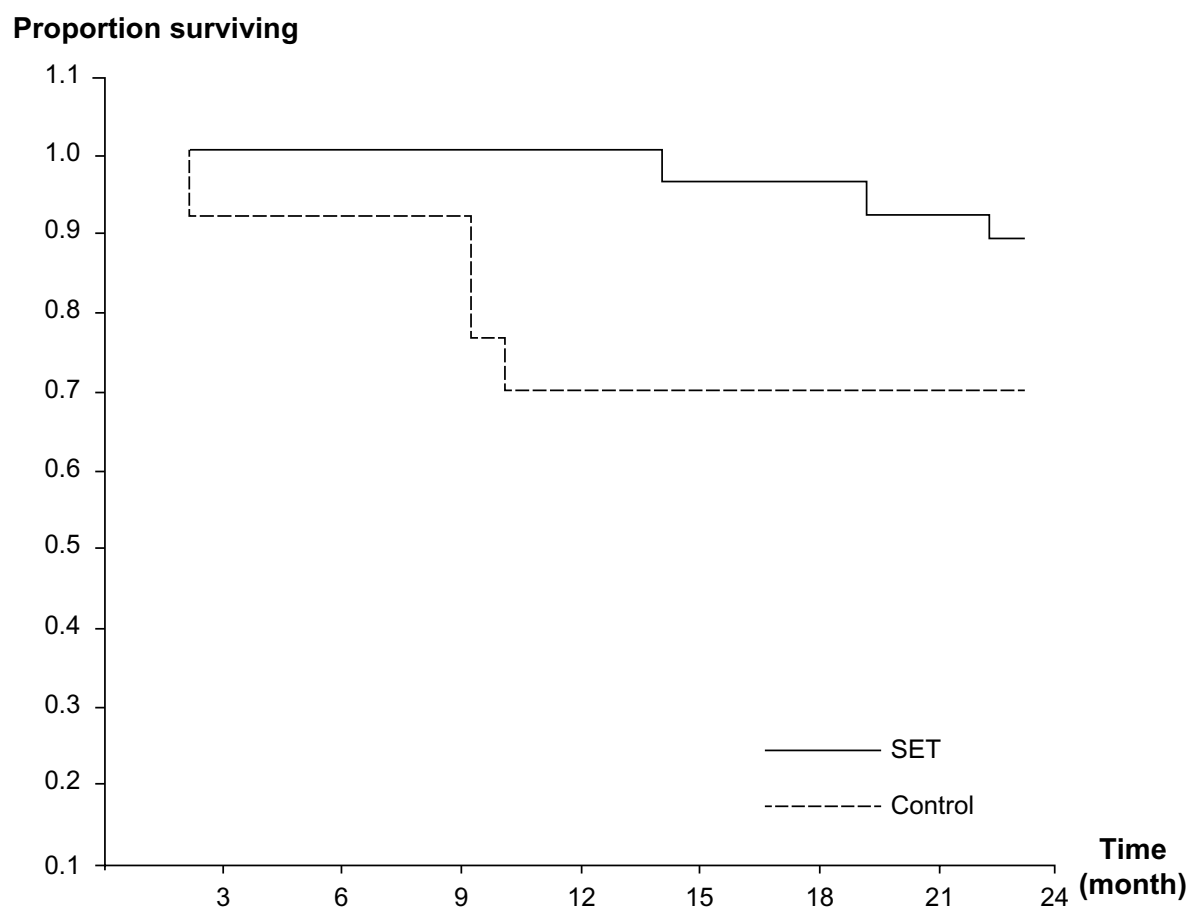

Figure 6 Kaplan-Meier survival curves for patients in SET and control groups during 2 years of follow-up. 
improved one month later. Some parameters (respiratory, upper and lower limb muscle strength, BDI/TDI, and QoL) were improved throughout the study period (24-month follow-up). In addition, these parameters were continually improved for quite a long period after SET ended. Although there was clinically significant improvement in the severity of dyspnea in the patients in the SET group measured by TDI, the dyspnea score measured by mMRC did not show clinically significant improvement. Therefore, we could conclude that the change in TDI is more sensitive than mMRC for measuring the dyspnea severity. For exercise capacities, we measured both 6-MWD and endurance time. The 6-MWD started to improve clinically from month 2 and persistentally improved up to month 9. The endurance time started to significantly improve from month 1 (one month earlier than 6-MWD) and persistently improved throughout the one-year testing period (at least 3 months longer than 6-MWD). The earlier and persistently longer improvement of endurance time than the 6-MWD might indirectly reflect that endurance time is a more sensitive parameter than 6-MWD for measuring change of exercise capacity in COPD. The severity of dyspnea significantly improved both clinically and statistically as indicated by the mean change in the TDI score but not by mMRC score. Other studies have suggested that the latter, by using a rougher scale, is not sensitive enough to detect changes in patients with advanced COPD. ${ }^{31}$ For the QoL, the patients in the SET group showed persistent improvement throughout all visits over the 2-year period. Varying results on survival were reported in previous retrospective, non-randomized survival analyses. ${ }^{1,32}$ Our results indicated that there was a slight but not significant difference in survival rate between the SET (89\%) and the control (71\%) groups. The absence of significant difference in survival rate between the SET and the control groups might be due to a small sample size, significant dropout rate, and only a 2-year follow-up. As expected, $\mathrm{FEV}_{1}$ was the most significant predictor of survival. Our SET program did not affect the measures of pulmonary function that were shown in previous studies to be significant predictors of survival in patients with COPD. ${ }^{33,34}$

ATS/ERS had suggested that the exercise training program should offer at least three sessions per week to achieve any physiologic benefits. ${ }^{35}$ This was modified later to twice weekly supervised plus one unsupervised home session. Our results were contrary to those of Ringbaek et $\mathrm{al}^{36}$ who did not find any improvement in exercise capacity while exercising twice a week for 8 weeks. The reason could be that our SET exercise program was more intensified and the patients were more deconditioned.
Although our study had benefits of training on 2-year follow-up, all outcome measurements showed peak response at month 9. These benefits, which were similar to other studies, suggested that after 9 months, the rehabilitation program should have some reinforcements after the core phase in the form of supervised periods of exercise, group sessions to discuss progress and problems, and the introduction of maintenance techniques. ${ }^{32}$

Our study had some limitations. First, the study was conducted in a single university-based center and it might not be applicable to large-scale practices, especially those that do not have specialized physiotherapists and nurses. Second, the study was not designed as a double-blinded randomized control trial with sham exercise in the control group; we had divided the patients following their preferences. The patients in SET group might have had more motivation for coping with their COPD than the control group and might have been more enthusiastic about continuing their self-exercise program after the first 2 months of the intensive supervised one. Third, our study had significantly high dropout rates in both groups. There were $19.5 \%$ versus $50 \%$ and $49.1 \%$ versus $64.3 \%$ of patients dropped out from the study by 12 months and 24 months in the SET group versus the control group, respectively. The proportion of respondents declining rehabilitation appears similar to other studies $(9 \%-50 \%){ }^{37-40}$

\section{Conclusion}

Our results confirm that the SET program, as an intensive ergometer exercise, is effective for patients with advanced COPD. This program proved to be a feasible approach for improving peripheral and respiratory muscle strengths, dyspnea, and QoL up to 2 years and exercise capacity up to at least the 9-month follow-up. These promising results should encourage the health care professionals to promote exercise training for patients with advanced COPD who are prone to limit most of their daily activities despite optimal medication control.

\section{Acknowledgments}

The authors wish to thank the patients who kindly took part in this study and to acknowledge the staff members of the Division of Pulmonary Critical Care and Allergy, Department of Internal Medicine, Faculty of Medicine, Chiang Mai University for their contribution to this trial. Our gratitude also goes to Jatuporn Wongsatitkul for her consultation for developing the SET program and Monsicha Somrit for providing her expertise as a skillful physiotherapist. 


\section{Author contributions}

CP (pulmonologist) developed study design and carried out acquisition and interpretation of data, statistical analysis, manuscript preparation, and critical revision of intellectual contents. WC (physical therapist) helped CP conducting acquisition and interpretation of data and critical reviews of the manuscript, revised the article for important intellectual content and gave final approval of the version to be published. The other authors contributed to acquisition and interpretation of data, revised the article for important intellectual content and gave final approval of the version to be published.

\section{Disclosure}

The authors have no conflicts of interest in connection with the work submitted.

\section{References}

1. Ries AL. Position paper of the American Association of Cardiovascular and Pulmonary Rehabilitation: scientific basis of pulmonary rehabilitation. J Cardiopulm Rehabil. 1990;10:418-441.

2. Pulmonary rehabilitation: joint ACCP/AACVPR evidence-based guidelines. ACCP/AACVPR pulmonary rehabilitation guidelines panel. American College of Chest Physicians. American Association of Cardiovascular and Pulmonary Rehabilitation. Chest. 2007;131:4-42.

3. British Thoracic Society Standards of Care Subcommittee on Pulmonary Rehabilitation. Pulmonary rehabilitation. Thorax. 2001;56:827-834.

4. Lacasse Y, Brosseau L, Milne S, et al. Pulmonary rehabilitation for chronic obstructive pulmonary disease. Cochrane Database Syst Rev. 2002;3:CD003793.

5. Troosters T, Grosselink R, Decramer M. Short and long-term effects of outpatient rehabilitation in patients with chronic obstructive pulmonary disease: a randomized trial. Am J Med. 2000;109:207-212.

6. Güell R, Casan P, Belda J, et al. Long-term effects of outpatient rehabilitation of COPD: a randomized trial. Chest. 2000;117:976-983.

7. Lacasse Y, Martin S, Lasserson TJ, Goldstein RS. Meta-analysis of respiratory rehabilitation in chronic obstructive pulmonary disease. A Cochrane systemic review. Eura Medicophys. 2007;43:475-485.

8. Buist SA; Global Initiative for Chronic Obstructive Lung Disease. Global Strategy for the Diagnosis, Management and Prevention of Chronic Obstructive Pulmonary Disease. Executive Summery; 2006.

9. Nici L, Donner C, Wouters E, et al. American Thoracic Society/ European Respiratory Society statement on pulmonary rehabilitation. Am J Respir Crit Care Med. 2006;173:1390-1413.

10. Pothirat C, Phetsuk N, Deesomchok A, et al. Clinical characteristics, management in real world practice and long-term survival among COPD patients of Northern Thailand COPD club members. J Med Assoc Thai. 2007;90:653-662.

11. Rabe KF, Hurd S, Anzueto A, et al; Global Initiative for Chronic Obstructive Lung Disease. Global strategy for the diagnosis, management, and prevention of chronic obstructive pulmonary disease. Am J Respir Crit Care Med. 2007;176:527-528.

12. Miller MR, Hankinson J, Brusasco V, et al. ATS/ERS task force: standardization of lung function test. Eur Respir J. 2005;26:319-338.

13. ATS Statement. Guidelines for the six-minute walk test. Am J Respir Crit Care Med. 2002;166:111-117.

14. Jones PW, Quirk FH, Baveystock CM. The St George's Respiratory Questionnaire. Respir Med. 1991;85(Suppl B):25-31.

15. Bestall JC, Paul EA, Garrod R, Garnham R, Jones PW, Wedzicha JA. Usefulness of the Medical Research Council (MRC) dyspnoea scale as a measure of disability in patients with chronic obstructive pulmonary disease. Thorax. 1999;54:581-586.
16. Mahler DA, Weinberg DH, Wells CK, Feinstein AR. The measurement of dyspnea: contents, inter observer agreement, and physiologic correlates of two new clinical indexes. Chest. 1984;85:751-758.

17. Black LF, Hyatt RE. Maximal respiratory pressures: normal values and relationship to age and sex. Am Rev Respir Dis. 1969;99:696-702.

18. American College of Sports Medicine. American College of Sports Medicine Guideline for Exercise Testing and Prescription. Benefit and Risks Associate with Physical Activity. Vol 30. Indianapolis: American College of Sports Medicine; 2006:4.

19. American College of Sports Medicine. American College of Sports Medicine Guideline for Exercise Testing and Prescription. Health-Related Physical Fitness Testing and Interpretation. Vol 30. Philadelphia: Wolters Kluwer/Lippincott Williams \& Wilkins Health; 2006:77.

20. Redelmeier DA, Bayoumi AM, Goldstein RS, Guyatt GH. Interpreting small differences in functional status: the six minute walk test in chronic lung disease patients. Am J Respir Crit Care Med. 1997;155: 1278-1282.

21. Schünemann HJ, Griffith L, Jaeschke R, Goldstein R, Stubbing D, Guyatt GH. Evaluation of the minimal important difference for the feeling thermometer and the St George's Respiratory Questionnaire in patients with chronic airflow obstruction. J Clin Epidemiol. 2003;56:1170-1176.

22. de Torres JP, Pinto-Plata V, Ingenito E, et al. Power of outcome measurements to detect clinically significant changes in pulmonary rehabilitation of patients with COPD. Chest. 2002;121(4):1092-1098.

23. Witek TJ, Mahler DA. Minimal important difference of the transition dyspnoea index in a multinational clinical trial. Euro Respir J. 2003;21:267-272.

24. Derom E, Marchand E, Troosters T. Pulmonary rehabilitation in chronic obstructive pulmonary disease. Ann Readapt Med Phys. 2007;50:615-626.

25. American College of Sports Medicine Position Stand. The recommended quantity and quality of exercise for developing and maintaining cardiorespiratory and muscular fitness, and flexibility in healthy adults. Med Sci Sports Exerc. 1998;30:975-991.

26. Coppoolse R, Schols AM, Baarends EM, et al. Interval versus continuous training in patients with severe COPD: a randomized clinical trial. Eur Respir J. 1999;14:258-263.

27. Ries AL, Kaplan RM, Myers R, Prewitt LM. Maintenance after pulmonary rehabilitation in chronic lung disease: a randomized trial. Am J Respir Crit Care Med. 2003;167:880-888.

28. Swerts PM, Kretzers LM, Terpstra-Lindeman E, Verstappen FT, Wouters EF. Exercise reconditioning in the rehabilitation of patients with chronic obstructive pulmonary disease: a short- and long-term analysis. Arch Phys Med Rehabil. 1990;71:550-573.

29. Strijbos JH, Postma DS, van Altena R, Gimeno F, Koëter GH. A comparison between an outpatient hospital-based pulmonary rehabilitation program and a home-care pulmonary rehabilitation in patients with COPD: a follow-up of 18 months. Chest. 1996;109:366-372.

30. Vale F, Reardon JZ, Zu Wallack RL. The long-term benefits of outpatient pulmonary rehabilitation on exercise endurance and quality of life. Chest. 1993;103:42-45.

31. Evans RA, Singh SJ, Collier R, Williams JE, Morgan MD. Pulmonary rehabilitation is successful for COPD irrespective of MRC dyspnoea grade. Respir Med. 2009;103:1070-1075.

32. Ries AL, Kaplan RM, Limberg TM, Prewitt LM. Effects of pulmonary rehabilitation on physiologic and psychosocial outcomes in patients with chronic obstructive pulmonary disease. Ann Intern Med. 1995;122: $823-832$.

33. Anthonisen NR, Wright EC, Hodgkin JE. Prognosis in chronic obstructive pulmonary disease. Am Rev Respir Dis. 1986;133:14-20.

34. Traver GA, Cline MG, Burrows B. Predictors of mortality in chronic obstructive pulmonary disease: a 15-year follow-up study. Am Rev Respir Dis. 1979;119:895-902.

35. ATS/ERS Pulmonary Rehabilitation Writing Committee. American Thoracic Society/European Respiratory Society statement on pulmonary rehabilitation. Am J Respir Crit Care Med. 2006;173:1390-1413. 
36. Ringbaek TJ, Broendum E, Hemmingsen L, et al. Rehabilitation of patients with chronic obstructive pulmonary disease. Exercise twice a week is not sufficient. Respir Med. 2000;94:150-154.

37. Cote CG, Celli BR. Pulmonary rehabilitation and the BODE index in COPD. Eur Respir J. 2005;26:630-636.

38. de Blok BM, de Greef MH, ten Hacken NH, Sprenger SR, Postema K, Wempe JB. The effects of a lifestyle physical activity counseling program with feedback of a pedometer during pulmonary rehabilitation in patients with COPD: a pilot study. Patient Educ Couns. 2006;61:48-55.
39. Trappenburg JC, Troosters T, Spruit MA, Vandebrouck N, Decramer M, Gosselink R. Psychosocial conditions do not affect short-term outcome of multidisciplinary rehabilitation in chronic obstructive pulmonary disease. Arch Phys Med Rehabil. 2005;86:1788-1792.

40. Bjoernshave B, Korsgaard J, Nielsen CV. Does pulmonary rehabilitation work in clinical practice? A review on selection and dropout in randomized controlled trials on pulmonary rehabilitation. Clin Epidemiol. 2010;2:73-83.

\section{Publish your work in this journal}

The International Journal of COPD is an international, peer-reviewed journal of therapeutics and pharmacology focusing on concise rapid reporting of clinical studies and reviews in COPD. Special focus is given to the pathophysiological processes underlying the disease, intervention programs, patient focused education, and self management protocols.

\section{Dovepress}

This journal is indexed on PubMed Central, MedLine and CAS. The manuscript management system is completely online and includes a very quick and fair peer-review system, which is all easy to use. Visit $\mathrm{http} / / / \mathrm{www}$.dovepress.com/testimonials.php to read real quotes from published authors.

Submit your manuscript here: http://www.dovepress.com/international-journal-of-copd-journal 